\title{
Acid Aspiration-induced Lung Injury in Rabbits is Mediated by Interleukin-8-dependent Mechanisms
}

\author{
Hans G. Folkesson, ${ }^{\star}$ Michael A. Matthay, ${ }^{*}$ Caroline A. Hébert, ${ }^{\star}$ and V. Courtney Broaddus ${ }^{5}$ \\ ${ }^{*}$ Cardiovascular Research Institute, University of California San Francisco, San Francisco, California 94143-0130; ${ }^{\ddagger}$ Genentech Inc., \\ So. San Francisco, California 94080; and ${ }^{8}$ Lung Biology Center and Department of Medicine, San Francisco General Hospital, \\ San Francisco, California 94110
}

\begin{abstract}
Acid aspiration lung injury may be mediated primarily by neutrophils recruited to the lung by acid-induced cytokines. We hypothesized that a major acid-induced cytokine was IL-8 and that a neutralizing anti-rabbit-IL-8 monoclonal antibody (ARIL8.2) would attenuate acid-induced lung injury in rabbits. Hydrochloric acid ( $\mathrm{pH}=1.5 \mathrm{in} 1 / 3$ normal saline) or $1 / 3$ normal saline $(4 \mathrm{ml} / \mathrm{kg}$ ) was instilled into the lungs of ventilated, anesthetized rabbits. The rabbits were studied for 6 or 24 h. In acid-instilled rabbits without the anti-IL-8 monoclonal antibody, severe lung injury developed in the first $6 \mathrm{~h}$; in the long-term experiments, all rabbits died with lung injury between 12 and $14 \mathrm{~h}$. In acid-instilled rabbits given the anti-IL-8 monoclonal antibody $(2 \mathrm{mg} / \mathrm{kg}$, intravenously) either as pretreatment $(5 \mathrm{~min}$ before the acid) or as treatment ( $1 \mathrm{~h}$ after the acid), acid-induced abnormalities in oxygenation and extravascular lung water were prevented and extravascular protein accumulation was reduced by $70 \%$; in the long-term experiments, anti- $\mathrm{IL-8}$ treatment similarly protected lung function throughout the 24-h period. The anti-IL-8 monoclonal antibody also significantly reduced air space neutrophil counts and $I L-8$ concentrations. This study establishes $\Pi \mathbf{L - 8}$ as a critical cytokine for the development of acid-induced lung injury. Neutralization of IL-8 may provide the first useful therapy for this clinically important form of acute lung injury. (J. Clin. Invest. 1995. 96:107-116.) Key words: acute lung injury • edema $\cdot$ neutrophil-activating protein-1 $\cdot$ lung endothelial permeability
\end{abstract}

\section{Introduction}

Aspiration of gastric contents is the second most common clinical event associated with the development of the adult respiratory distress syndrome (ARDS) and the mortality for ARDS resulting from acid aspiration ranges from $40-50 \%(1,2)$. Although the acid itself may directly injure the lung, acid aspira-

Address correspondence to Hans G. Folkesson, Cardiovascular Research Institute, University of California San Francisco, 505 Parnassus Avenue, HSW-1346, Box 0130, San Francisco, CA 94143-0130. Phone: 415476-2807; FAX: 415-476-0722.

Received for publication 19 September 1994 and accepted in revised form 8 March 1995.

J. Clin. Invest.

(C) The American Society for Clinical Investigation, Inc.

0021-9738/95/07/0107/10 \$2.00

Volume 96, July 1995, 107-116 tion-induced acute lung injury may be mediated in part by neutrophil-dependent mechanisms. In several studies, acid-induced lung injury has been reduced either by blocking neutrophil products or by depleting neutrophils (3-9). Presumably, acid aspiration induces neutrophil recruitment into the lung by inducing the release of a variety of chemotactic and inflammatory molecules chiefly from alveolar macrophages $(3,5-7)$. Once recruited to the lung, neutrophils may then induce injury upon binding to or migrating through the pulmonary capillary endothelium (10-12). The major chemotactic stimulus for neutrophil recruitment into the lung after acid aspiration has not been determined.

IL-8 has been proposed as a major chemotactic factor for recruitment of neutrophils to extravascular sites of inflammation, including those in the lung $(13,14)$. Not only is IL-8 a potent chemoattractant for neutrophils, it also up-regulates neutrophil $\beta_{2}$ adhesion receptors for endothelium (15), mediates neutrophil migration across activated endothelium $(16,17)$, and primes neutrophils for activation $(18,19)$. IL-8 is also known to be produced by several cells in the lung, including alveolar macrophages, alveolar type II epithelial cells, bronchial epithelial cells, and pulmonary fibroblasts (20-24). In clinical studies, measurements of IL-8 in edema fluid and bronchoalveolar lavage fluid support an important role for IL-8 in acute lung injury $(12,25,26)$. In one study of patients with acute lung injury (12), higher IL-8 concentrations were associated with an increase in mortality, and in a study of patients at risk for acute lung injury, $\mathrm{IL}-8$ concentrations were higher in those who developed adult respiratory distress syndrome than in those who did not (26). In two recent experimental studies in rats and rabbits, antibodies to human IL-8 reduced neutrophil influx and lung injury caused by IgG immune complexes (27) and ischemia reperfusion (28). Based on these data, we hypothesized that the lung injury after acid aspiration was mediated by neutrophils recruited to the lung by IL-8.

The first objective of these studies was to determine if pretreatment with an anti-IL-8 antibody would reduce the magnitude of acute lung injury after acid aspiration. The anti-rabbitIL-8 antibody used in this studies (ARIL8.2) was developed by us to be species-specific and was shown to be effective in decreasing endotoxin-induced neutrophil influx into the pleural space of rabbits by $>75 \%$ (29). Since the results of the pretreatment studies demonstrated a significant reduction in the severity of the acute lung injury from acid aspiration, the second objective was to determine if treatment with the anti-IL-8 antibody given $1 \mathrm{~h}$ after acid instillation would be effective in both short-term $(6 \mathrm{~h})$ and long-term experiments $(24 \mathrm{~h})$. These studies were designed to measure the three critical indices of acute lung injury: gas exchange, lung fluid balance, and endothelial barrier permeability to protein. To confirm the biologic 
activity of the anti-IL-8 antibody, the number of neutrophils and the concentration of free IL- 8 (not bound by the anti-IL8 monoclonal antibody) were measured in the air spaces at the end of the experiment.

\section{Methods}

Animals, surgical preparations and ventilation. Male New Zealand white rabbits ( $n=34$, weighing $2.5-3.5 \mathrm{~kg}$; Nitabell, Hayward, CA) were surgically prepared as described earlier (30). Briefly, the rabbits were initially anesthetized using $4 \%$ halothane in $100 \% \mathrm{O}_{2}$; the anesthesia was then maintained with $0.8 \%$ halothane in $100 \% \mathrm{O}_{2}$. Pancuronium bromide $\left(0.3 \mathrm{mg} / \mathrm{h} \times \mathrm{kg}\right.$ body weight; Pavulon ${ }^{\circledR}$; Organon Diagnostic, West Orange, NJ) was given intravenously for neuromuscular blockade.

A 22-gauge Angiocath ${ }^{\circledR}$ (Deseret Medical, Inc., Becton Dickinson and Co., Sandy, UT) was inserted in the marginal ear vein for administering fluid and drugs. A PE-90 (Clay Adams, Becton Dickinson and Co., Parsippany, NJ) catheter was inserted in the right carotid artery to monitor systemic blood pressure and to obtain blood samples. A 4.0$\mathrm{mm}$ inside diameter endotracheal tube was inserted through a tracheostomy. The rabbits were maintained in the prone position during the experiments and ventilated with a constant-volume piston pump (Harvard Apparatus Co., S. Natick, MA) with an inspired oxygen fraction of 1.0 and with a peak airway pressure of $15-18 \mathrm{~cm} \mathrm{H}_{2} \mathrm{O}$ during the baseline period, and supplemented with a positive end-expiratory pressure of $4 \mathrm{~cm} \mathrm{H}_{2} \mathrm{O}$. During the baseline period, the respiratory rate was adjusted to maintain the arterial $\mathrm{PCO}_{2}$ between $35-40 \mathrm{mmHg}$. Thereafter, the ventilator settings were kept constant throughout the experiment.

The protocol for the studies was approved by the University of California San Francisco Animal Research Committee.

Preparation of the instillate. A solution of $100 \mathrm{mOsm} / \mathrm{kg}$ of $\mathrm{NaCl}$ ( $1 / 3$ normal saline) was prepared with isotonic $0.9 \%$ saline and distilled water. The $1 / 3$ normal osmolality was chosen to match the osmolality of gastric aspirates. Then, $\mathrm{HCl}$ was added to the solution and titrated to a $\mathrm{pH}$ of 1.5 . In the negative control studies, $1 / 3$ normal saline was used as the instillate. Evans blue dye ( $1 \mathrm{mg}$; Aldrich Chemical Co. Inc., Milwaukee, WI) was added to all instillates to confirm at postmortem examination that the instilled fluid was distributed equally to both lungs.

Generation of the monoclonal antibody to rabbit rIL-8. The generation of the mAb to rabbit recombinant IL-8 (rIL-8) ${ }^{1}$ (ARIL8.2) has been described in detail (29). ARIL8.2 was selected by virtue of its ability to recognize rabbit IL-8, to inhibit binding of ${ }^{125}$ I-labeled rabbit rIL-8 to its receptor, to block rabbit rIL-8-induced signal transduction via its receptor, and to inhibit rabbit rIL-8-induced chemotactic activity for rabbit neutrophils (29). ARIL8.2 had a high affinity for rabbit IL$8\left(K_{\mathrm{d}}=0.42 \mathrm{nM}\right)$. ARIL8.2 did cross-react with human IL-8, but not with closely related cytokines (hMGSA, platelet factor- $4, \beta$-thromboglobulin), other human cytokines (IL-1 $\beta$, TNF- $\alpha$ ), or other chemotactic factors (FMLP, C5a). The antibody preparation was sterile filtered and by Limulus assay endotoxin was undetectable.

General experimental protocol. In all experiments, after the surgical preparations, a 1-h baseline of stable heart rate, systemic blood pressure, and arterial blood gases was required before the instillation. $15 \mathrm{~min}$ into the baseline period, $3 \mu \mathrm{Ci}{ }^{131} \mathrm{I}$-labeled human serum albumin $\left({ }^{131} \mathrm{I}\right.$ albumin; Frosst Laboratories, Montreal, Canada) was injected intravenously as a vascular tracer protein. Blood samples were obtained every $15 \mathrm{~min}$ for the remaining $45 \mathrm{~min}$ of the baseline period. The vascular tracer was used to calculate the flux of plasma protein into the extravascular spaces of the lung.

For the instillation, a tubing ( 5 Fr., Accumark $\AA^{\circ}$ Premarked Feeding Catheter; Concord/Portex, Keene, NH) was gently passed through the

\footnotetext{
1. Abbreviation used in this paper: rIL, recombinant IL.
}

tracheal tube until it was placed $\sim 1 \mathrm{~cm}$ above the carina. Then, $\mathrm{HCl}$ or $1 / 3$ normal saline $(4 \mathrm{ml} / \mathrm{kg}$ body weight) was instilled into both lungs over $3 \mathrm{~min}$. After the instillation was completed, the tubing was withdrawn.

$30 \mathrm{~min}$ after the instillation and hourly thereafter during the 6- or 24-h experimental periods, blood was sampled.

At the end of the 6- or 24-h experiments, the abdomen was opened and the rabbit was exsanguinated by transection of the abdominal aorta. The lungs were removed through a median sternotomy. An alveolar sample was aspirated via a sampling catheter gently passed through the trachea to a wedged position in a distal airway. Then, the left lung was clamped at the main bronchus for later use in extravascular lung water and tracer protein measurements (see below). The right lung was then lavaged two times, using $6 \mathrm{ml}$ of isoosmolar $0.9 \% \mathrm{NaCl}$ containing 12 mM lidocaine (Sigma Chemical Co., St. Louis, MO) each time.

The radioactivity of the samples was measured. Total and differential cell counts were measured on the blood and bronchoalveolar lavage samples. The total cell counts were calculated as cells per milliliter lavage multiplied by the lavage volume used $(12 \mathrm{ml})$. Free, unbound IL-8 levels were measured in the plasma samples and the alveolar samples (see below).

By TCA precipitation of the instillates and selected samples from each experiment, it was established that the vascular tracer ${ }^{131}$ I remained $>98 \%$ bound to protein.

Specific experimental protocol. There were seven experimental groups. Six of these groups received $\mathrm{HCl}$ instillation and one received $1 / 3$ normal saline instillation.

In the positive control group $(n=10), 5 \mathrm{~min}$ before the $\mathrm{HCl}$ instillation, the rabbits received either $0.9 \% \mathrm{NaCl}(2 \mathrm{ml} / \mathrm{kg}$ body wt) or an irrelevant monoclonal antibody ( $2 \mathrm{mg} / \mathrm{kg}$ body wt) intravenously and were studied for $6 \mathrm{~h}$. The irrelevant monoclonal antibody was of the same isotype as ARIL8.2 (IgG2a) and directed against the gp120 envelope protein on the human immunodeficiency virus (29). Because there were no differences in the studied parameters, the rabbits given the irrelevant monoclonal antibody and those given $\mathrm{NaCl}$ intravenously were combined into one group.

In the pretreatment group $(n=6), 5 \mathrm{~min}$ before the $\mathrm{HCl}$ instillation, the rabbits received the monoclonal antibody against IL-8 (ARIL8.2, 2 $\mathrm{mg} / \mathrm{kg}$ body $\mathrm{wt}$ ) intravenously and were studied for $6 \mathrm{~h}$.

In the treatment group $(n=6), 1 \mathrm{~h}$ after the $\mathrm{HCl}$ instillation, the rabbits received ARIL8.2 ( $2 \mathrm{mg} / \mathrm{kg}$ body wt) intravenously and were studied for $6 \mathrm{~h}$

In the negative control group $(n=4), 5 \mathrm{~min}$ before the $1 / 3$ normal saline instillation, the rabbits received $0.9 \% \mathrm{NaCl}(2 \mathrm{ml} / \mathrm{kg}$ body wt) intravenously and were studied for $6 \mathrm{~h}$.

In the neutrophil-depleted group $(n=4)$, all circulating neutrophils had first been depleted by administering vinblastine sulfate $(0.75 \mathrm{mg} /$ $\mathrm{kg}$ body wt; Sigma Chemical Co.) in the marginal ear vein $4 \mathrm{~d}$ before the experiment. On the day before the experiment, the depletion of circulating neutrophils was confirmed by finding no neutrophils on a blood smear stained with modified May-Grünwald Giemsa. On the day of the experiment, the rabbits received the $\mathrm{HCl}$ instillation and were studied for $6 \mathrm{~h}$.

In the positive control (long-term) group $(n=3), 1 \mathrm{~h}$ after the $\mathrm{HCl}$ instillation, the rabbits received the irrelevant monoclonal antibody, antigp120 ( $2 \mathrm{mg} / \mathrm{kg}$ body $\mathrm{wt})$ intravenously. The experiments were planned for $24 \mathrm{~h}$, however all rabbits in this group died between 12-14 h after the $\mathrm{HCl}$ instillation.

In the treatment (long-term) group $(n=3), 1 \mathrm{~h}$ after the $\mathrm{HCl}$ instillation, the rabbits received ARIL8.2 $(2 \mathrm{mg} / \mathrm{kg}$ body wt) intravenously. The rabbits were then studied for $24 \mathrm{~h}$.

Hemodynamics, airway pressure, and arterial blood gases. The heart rate, systemic blood pressure, and airway pressure were measured using calibrated pressure transducers (Pd23 inside diameter; Gould Inc., Oxnard, CA) and recorded continuously on a polygraph (model 7; Grass Instrument Co., Quincy, MA). Arterial blood gases and $\mathrm{pH}$ and the 
systemic arterial pressure were measured every $30 \mathrm{~min}$. The alveolararterial oxygen difference was calculated.

Extravascular lung water. Our method for the determination of extravascular lung water has been described previously in detail (31, 32). In brief, the left lung was homogenized and the extravascular lung water was determined by measuring the extravascular water-to-dry weight ratio (gram water/gram dry lung). Because the right lung was lavaged for cell counts, the data for extravascular lung water was obtained for the left lung only. The bronchoalveolar lavage from the right lung and the homogenates from both lungs were used for measurement of radioactivity (see below).

Lung vascular permeability. For measurement of lung endothelial permeability to protein, the clearance of the vascular tracer protein, ${ }^{131} \mathrm{I}$ albumin, across the endothelium into the extravascular compartments of the lungs was measured. The total extravascular ${ }^{131} \mathrm{I}$-albumin accumulation in the lung was calculated by taking the total lung ${ }^{131} \mathrm{I}$-albumin (in lung homogenate and in the alveolar samples) and subtracting the vascular space ${ }^{131} \mathrm{I}$-albumin. The ${ }^{131} \mathrm{I}$-albumin in the vascular space was calculated by multiplying the counts in the final plasma sample by the calculated plasma volume in the lungs, as we have done previously ( 31 , 32). The extravascular accumulation of ${ }^{131} \mathrm{I}$-albumin in the lung was expressed as plasma equivalents, or the milliliters of plasma that would account for the radioactivity in the lung.

Measurement of free IL-8 concentrations. The concentrations of free IL-8, not bound by the anti-IL-8 monoclonal antibody, were measured by ELISA in plasma, in the final alveolar sample, and in the bronchoalveolar lavage fluid as described (29). In this assay ARIL8.2 was used as the primary capture mAb so that it would not capture IL-8 already bound to ARIL8.2. Microtiter plates (96-well; Alameda Chemical \& Science, Oakland, CA) were coated with ARIL8.2 $(10 \mu \mathrm{g} / \mathrm{ml})$, and then blotted dry and blocked with PBS containing $0.5 \%$ BSA (Sigma Chemical Co.) for $1 \mathrm{~h}$. Standards of rabbit rIL-8 mixed with ARIL8.2, plasma samples and alveolar samples in several dilutions were added to the wells for a 1-h incubation. After washing, the secondary antibody (8C1.1.6), conjugated to long-arm biotin (Biotin-S-NHS; Research Organics, Inc., Cleveland, $\mathrm{OH}$ ), was added for $2 \mathrm{~h}$ followed by horseradish peroxidase-conjugated streptavidin (1:5,000; Zymed Laboratories, Inc., South San Francisco, CA) for $1 \mathrm{~h}$. Tetramethyl benzidine (TMB, 2 component system; Kirkegaard \& Perry Laboratories, Inc., Gaithersburg, MD) was then added and color was allowed to develop in room temperature for $10 \mathrm{~min}$. Optical density was then measured with an ELISA plate reader at a wave length of $405 \mathrm{~nm}$. Sample values were determined by interpolation using a 4-parameter program (Genentech Inc., South San Francisco, CA) from a standard curve generated over a range of $2,000-31 \mathrm{pg} / \mathrm{ml}$. For the nonneutralized samples, the results for the dilutions were averaged over their linear range. However, when detecting antigen in the presence of a soluble antibody identical to the capture antibody, an ELISA can be nonlinear at increasing dilutions, perhaps because antigen dissociates from the soluble antibody and is subsequently bound by the capture antibody. Therefore, for the neutralized samples, we chose the lowest dilution (1:10) for quantitating free IL-8, knowing that this may still be an overestimate of the free IL-8 present. When testing the ELISA with standards of rabbit rIL-8 mixed with ARIL8.2, we found that, as ARIL8.2 concentrations increased, the free IL-8 detected decreased until, at a molar ratio of 5:1 and higher (mAb:IL-8), no IL-8 could be detected. All samples were coded so that the experimental condition was not known by the individual doing the assays.

Statistical analysis. One-way ANOVA with repeated measurements analysis was used to compare samples obtained at several time points from the same animal. One-way ANOVA (factorial) was used when comparing other single groups. Student-Newman-Keuls test was used as a post hoc statistical test. Values are expressed as either means \pm SD or means $\pm S E M$ as indicated in tables and figure legends. The data from the 6-h $\mathrm{HCl}$-instilled rabbits pretreated with either the irrelevant monoclonal antibody, anti-gp120, or with saline were combined because there were no significant differences between the groups.
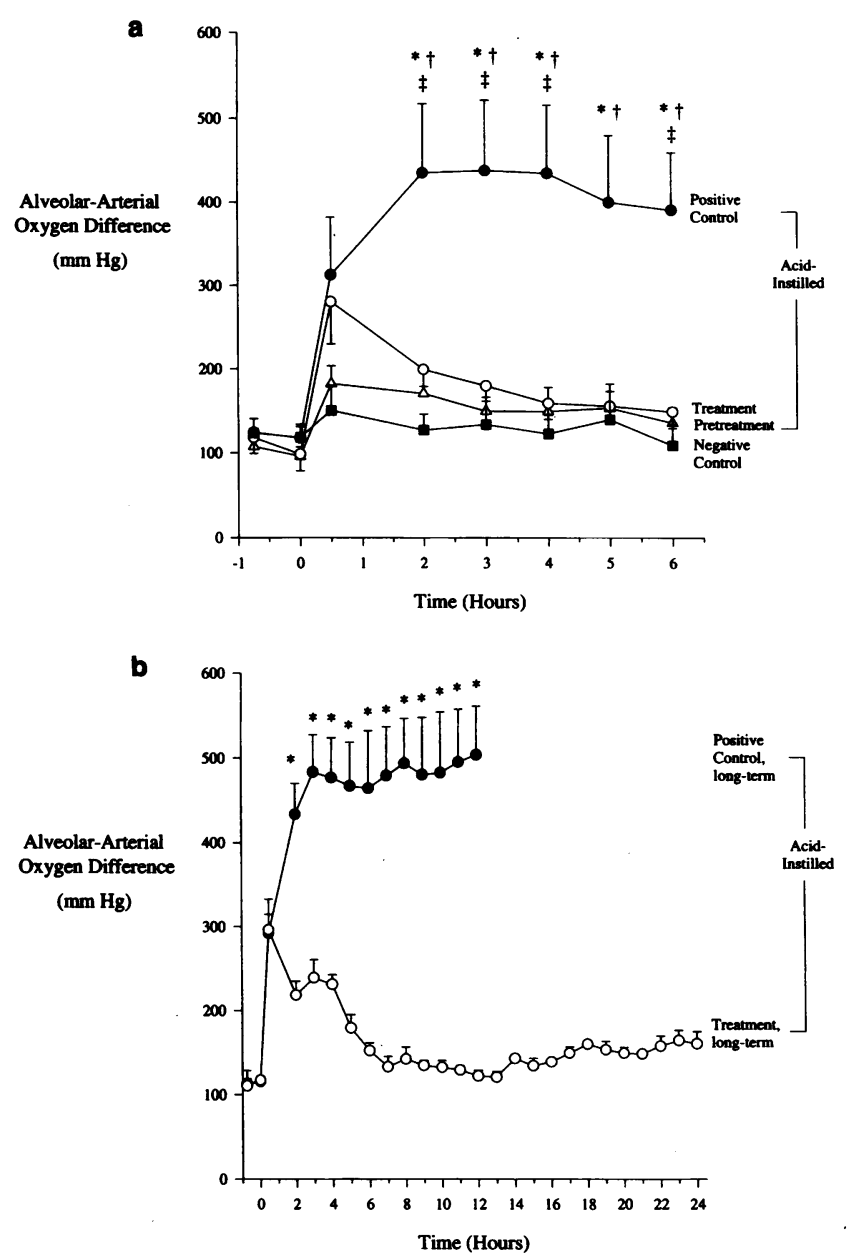

Figure 1. Alveolar-arterial oxygen tension difference in the positive control, pretreatment, treatment, and negative control groups over $6 \mathrm{~h}$ $(a)$ and over $24 \mathrm{~h}(b)$. In the 6-h experiments, the alveolar-arterial oxygen tension difference in the pretreatment and treatment groups was significantly less than that in the positive control group from $2 \mathrm{~h}$ onwards and was no different from that in the negative control group $(a)$. In the 24-h experiments, the alveolar-arterial oxygen tension difference was significantly less in the treatment (long-term) group than in the positive control (long-term) group by $2 \mathrm{~h}$ and remained low for $24 \mathrm{~h}$. All the rabbits $(n=3)$ in the positive control (long-term) group died at 12 $14 \mathrm{~h}(b)$. Data are means \pm SEM, ${ }^{*} P<0.05$ vs the negative control group ( $a$ ) or the treatment (long-term) group $(b),{ }^{\dagger} P<0.05$ vs the pretreatment group $(a),{ }^{\ddagger} P<0.05$ vs the treatment group $(a)$.

\section{Results}

Oxygenation, ventilation and $\mathrm{pH}$. In the short-term experiments, the alveolar-arterial oxygen tension differences in the ARIL8.2 pretreatment and treatment groups were significantly lower than in the positive control group by $2 \mathrm{~h}$ after the acid instillation and remained lower for the 6-h experiment (Fig. $1 a$ and Table I). In both the ARIL8.2 pretreatment and treatment groups, the alveolar-arterial oxygen tension difference was not significantly different from that in the negative control group (Fig. 1 $a$ and Table I). In the neutrophil-depleted group, the alveolararterial oxygen tension difference was also significantly lower than in the positive control group but higher than in the ARIL8.2 pretreatment and treatment groups (Table I). 
Table I. Oxygenation, Ventilation, Arterial pH, Systemic Blood Pressure, Heart Rate, and Airway Pressure in the Short-Term Experiments

\begin{tabular}{|c|c|c|c|c|c|c|}
\hline Condition & $\begin{array}{l}\text { Alveolar-arterial } \\
\text { oxygen difference }\end{array}$ & $\begin{array}{l}\text { Arterial } \\
\mathrm{PCO}_{2}\end{array}$ & $\mathrm{pH}$ & $\begin{array}{l}\text { Mean systemic } \\
\text { arterial pressure }\end{array}$ & Heart rate & $\begin{array}{c}\text { Peak airway } \\
\text { pressure }\end{array}$ \\
\hline & $m m H g$ & $m m H g$ & & $m m H g$ & beats/min & $\mathrm{cm} \mathrm{H}_{2} \mathrm{O}$ \\
\hline \multicolumn{7}{|c|}{ Positive control group $(\mathrm{HCl}), n=10$} \\
\hline Baseline & $107 \pm 31$ & $37 \pm 4$ & $7.44 \pm 0.06$ & $68 \pm 13$ & $300 \pm 30$ & $17 \pm 3$ \\
\hline $6 \mathrm{~h}$ after instillation & $390 \pm 137 *$ & $67 \pm 18^{*}$ & $7.19 \pm 0.13 *$ & $56 \pm 21$ & $285 \pm 23$ & $26 \pm 8^{*}$ \\
\hline \multicolumn{7}{|c|}{ Pretreatment group (ARIL8.2, $\mathrm{HCl}$ ), $n=6$} \\
\hline Baseline & $107 \pm 35$ & $36 \pm 4$ & $7.44 \pm 0.05$ & $61 \pm 13$ & $307 \pm 38$ & $17 \pm 2$ \\
\hline $6 \mathrm{~h}$ after instillation & $136 \pm 48^{\ddagger}$ & $38 \pm 8^{* \ddagger}$ & $7.37 \pm 0.04^{\ddagger}$ & $52 \pm 10$ & $276 \pm 35$ & $22 \pm 4 *$ \\
\hline \multicolumn{7}{|c|}{ Treatment group ( $\mathrm{HCl}$, ARIL8.2), $n=6$} \\
\hline Baseline & $108 \pm 40$ & $32 \pm 3$ & $7.46 \pm 0.08$ & $63 \pm 12$ & $304 \pm 34$ & $16 \pm 1$ \\
\hline $6 \mathrm{~h}$ after instillation & $149 \pm 40^{\ddagger}$ & $39 \pm 5^{* \ddagger}$ & $7.36 \pm 0.03^{\ddagger}$ & $52 \pm 18$ & $288 \pm 28$ & $23 \pm 3 *$ \\
\hline \multicolumn{7}{|c|}{ Neutrophil Depletion Group (HCl), $n=4$} \\
\hline Baseline & $110 \pm 54$ & $30 \pm 3$ & $7.47 \pm 0.07$ & $64 \pm 15$ & $301 \pm 23$ & $16 \pm 2$ \\
\hline $6 \mathrm{~h}$ after instillation & $241 \pm 64^{* \ddagger}$ & $33 \pm 6^{\ddagger}$ & $7.36 \pm 0.05^{\ddagger}$ & $53 \pm 13$ & $280 \pm 19$ & $22 \pm 2 *$ \\
\hline \multicolumn{7}{|c|}{ Negative Control Group ( $1 / 3$ normal saline), $n=4$} \\
\hline Baseline & $109 \pm 22$ & $36 \pm 2$ & $7.41 \pm 0.09$ & $61 \pm 4$ & $300 \pm 29$ & $17 \pm 2$ \\
\hline $6 \mathrm{~h}$ after instillation & $108 \pm 51^{\ddagger}$ & $41 \pm 3^{* \ddagger}$ & $7.38 \pm 0.05^{\ddagger}$ & $62 \pm 12$ & $298 \pm 21$ & $20 \pm 2 * \pm$ \\
\hline
\end{tabular}

Data are means $\pm \mathrm{SD} ;{ }^{*} P<0.05$ vs baseline; ${ }^{\ddagger} P<0.05$ vs positive control group.

In the long-term experiments, the alveolar-arterial oxygen tension difference was significantly lower in the treatment (long-term) group than in the positive control (long-term) group by $2 \mathrm{~h}$ after $\mathrm{HCl}$ instillation (Fig. $1 b$ and Table II). In the positive control (long-term) group, the rabbits died with severe hypoxemia between $12-14 \mathrm{~h}$. In the treatment (long-term) group, on the other hand, the rabbits lived for $24 \mathrm{~h}$ without hypoxemia.

The acid-induced abnormalities in $\mathrm{PaCO}_{2}$ and $\mathrm{pH}$ were prevented by either pretreatment with ARIL8.2 both in the 6- and 24-h studies, as well as by neutrophil depletion (Tables I and II).

Extravascular lung water. In the short-term experiments, the extravascular lung water (water-to-dry weight ratio) in the pretreatment and treatment groups was $35 \%$ lower than in the positive control group and not significantly different from that in the negative control group at $6 \mathrm{~h}$ (Fig. $2 a$ ). In the neutrophildepleted group, the extravascular lung water $(4.8 \pm 0.2$ grams water/gram dry lung) was also no different from that in the negative control group. In the long-term experiments, the extravascular lung water in the treatment (long-term) group at $24 \mathrm{~h}$ was $100 \%$ lower than in the positive control (long-term) group at $12-14 \mathrm{~h}$ (Fig. $2 \mathrm{~b}$ ).

Lung vascular permeability. In the short-term experiments, the extravascular accumulation of plasma equivalents in the lungs of the pretreatment and treatment groups was $70 \%$ lower than in the positive control group at $6 \mathrm{~h}$ (Fig. $3 \mathrm{a}$ ), although the extravascular accumulation of plasma was significantly

Table II. Oxygenation, Ventilation, Arterial pH, Systemic Blood Pressure, Heart Rate, and Airway Pressure in the Long-Term Experiments

\begin{tabular}{|c|c|c|c|c|c|c|}
\hline Condition & $\begin{array}{l}\text { Alveolar-arterial } \\
\text { oxygen difference }\end{array}$ & $\begin{array}{l}\text { Arterial } \\
\mathrm{PCO}_{2}\end{array}$ & $\mathrm{pH}$ & $\begin{array}{l}\text { Mean systemic } \\
\text { arterial pressure }\end{array}$ & Heart rate & $\begin{array}{l}\text { Peak airway } \\
\text { pressure }\end{array}$ \\
\hline & $m m H g$ & $m m H g$ & & $m m H g$ & beats/min & $\mathrm{cm} \mathrm{H}_{2} \mathrm{O}$ \\
\hline \multicolumn{7}{|c|}{ Positive control (long-term) group $(\mathrm{HCl}), n=3$} \\
\hline Baseline & $110 \pm 12$ & $31 \pm 2$ & $7.42 \pm 0.05$ & $55 \pm 16$ & $292 \pm 7$ & $18 \pm 2$ \\
\hline $6 \mathrm{~h}$ after instillation & $484 \pm 88^{*}$ & $68 \pm 1^{*}$ & $7.22 \pm 0.03 *$ & $59 \pm 23$ & $284 \pm 18$ & $28 \pm 4 *$ \\
\hline $12 \mathrm{~h}$ after instillation ${ }^{8}$ & $504 \pm 115^{*}$ & $87 \pm 19 *$ & $7.12 \pm 0.10^{*}$ & $48 \pm 7$ & $256 \pm 30$ & $31 \pm 5^{*}$ \\
\hline \multicolumn{7}{|c|}{ Treatment (long-term) group (HCl, ARIL8.2), $n=3$} \\
\hline Baseline & $112 \pm 18$ & $30 \pm 4$ & $7.42 \pm 0.02$ & $56 \pm 8$ & $284 \pm 7$ & $17 \pm 1$ \\
\hline $6 \mathrm{~h}$ after instillation & $152 \pm 19^{* \neq}$ & $33 \pm 2 * \pm$ & $7.36 \pm 0.06^{\ddagger}$ & $57 \pm 4$ & $288 \pm 21$ & $21 \pm 1 * \ddagger$ \\
\hline $12 \mathrm{~h}$ after instillation & $122 \pm 14^{\ddagger}$ & $33 \pm 2 * \pm$ & $7.34 \pm 0.04^{* \ddagger}$ & $54 \pm 4$ & $280 \pm 18^{\ddagger}$ & $21 \pm 1^{* \ddagger}$ \\
\hline $24 \mathrm{~h}$ after instillation & $161 \pm 29 *$ & $30 \pm 2$ & $7.36 \pm 0.01 *$ & $49 \pm 6$ & $272 \pm 14$ & $21 \pm 3 *$ \\
\hline
\end{tabular}

Data are means $\pm \mathrm{SD} ; * P<0.05$ vs baseline; ${ }^{\ddagger} P<0.05$ vs positive control (long-term) group; ${ }^{8}$ all rabbits in this group died between $12-14 \mathrm{~h}$. 

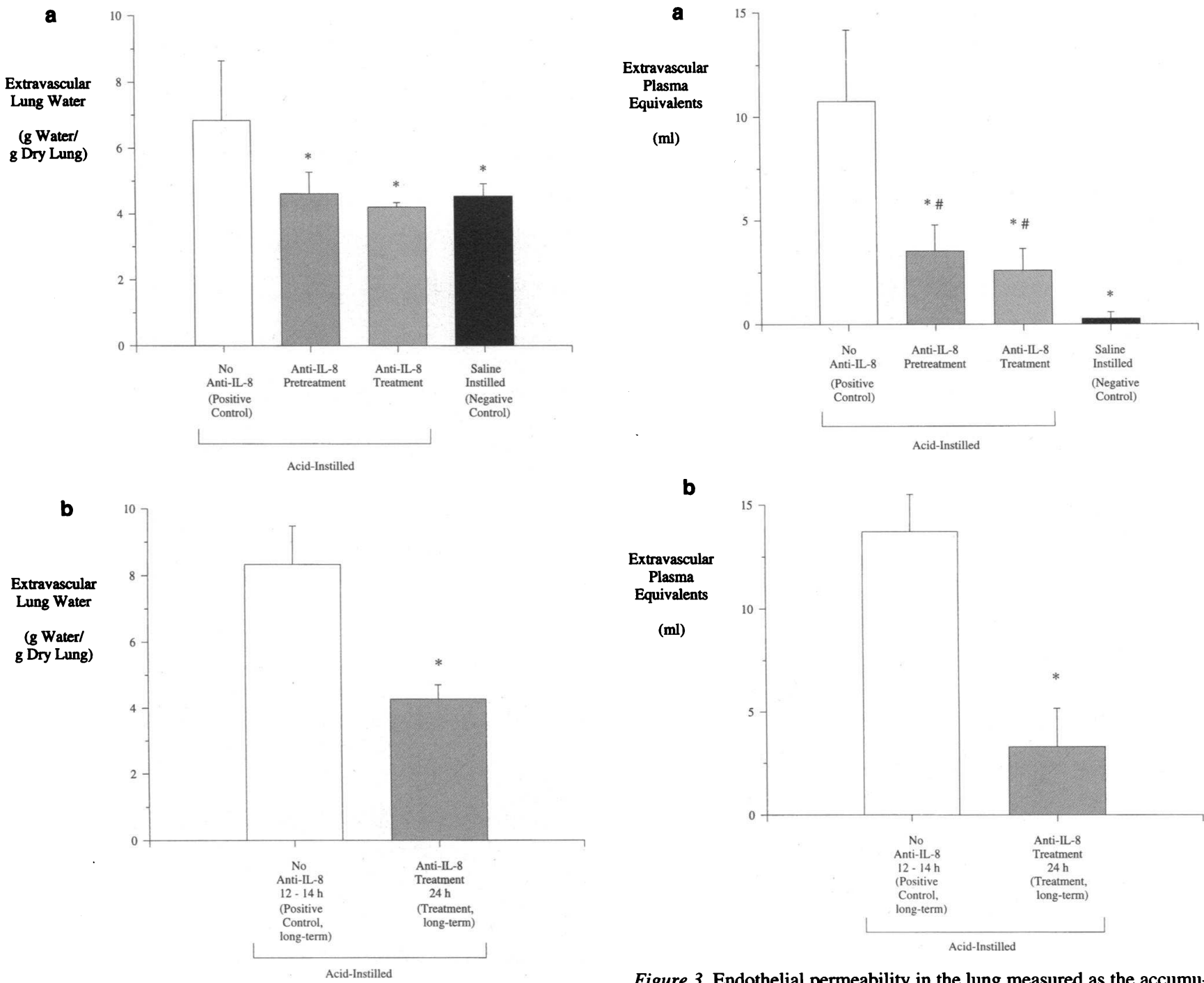

Figure 2. The extravascular lung water in the positive control, pretreatment, treatment, and negative control groups at $6 \mathrm{~h}(a)$ and in the positive control (long-term) group at 12-14 h and treatment (longterm) group at $24 \mathrm{~h}(b)$. In the short-term studies, the extravascular lung water in the pretreatment and treatment groups was 35\% lower than in the positive control groups and no different from that in the negative control group $(a)$. The extravascular lung water of a normal uninstilled rabbit lung is 3.2 grams water/gram dry lung. In the longterm studies, the extravascular lung water was $100 \%$ lower in the treatment (long-term) group than in the positive control (long-term) group (b). Data are means $\pm \mathrm{SD},{ }^{*} P<0.05$ vs the positive control group $(a)$ or the positive control (long-term) group $(b)$.

higher than in the negative control group. In the neutrophildepleted group, the extravascular accumulation of plasma equivalents $(5.3 \pm 1.6 \mathrm{ml})$ was not different from that measured in the pretreatment and treatment groups. In the long-term experiments, the extravascular accumulation of plasma equivalents in the lung was $75 \%$ lower in the treatment (long-term) group at $24 \mathrm{~h}$ than in the positive control (long-term) group at 12-14 h (Fig. 3 b).

Systemic blood pressure, heart rate, and peak airway pressure. No differences were observed in the blood pressure or

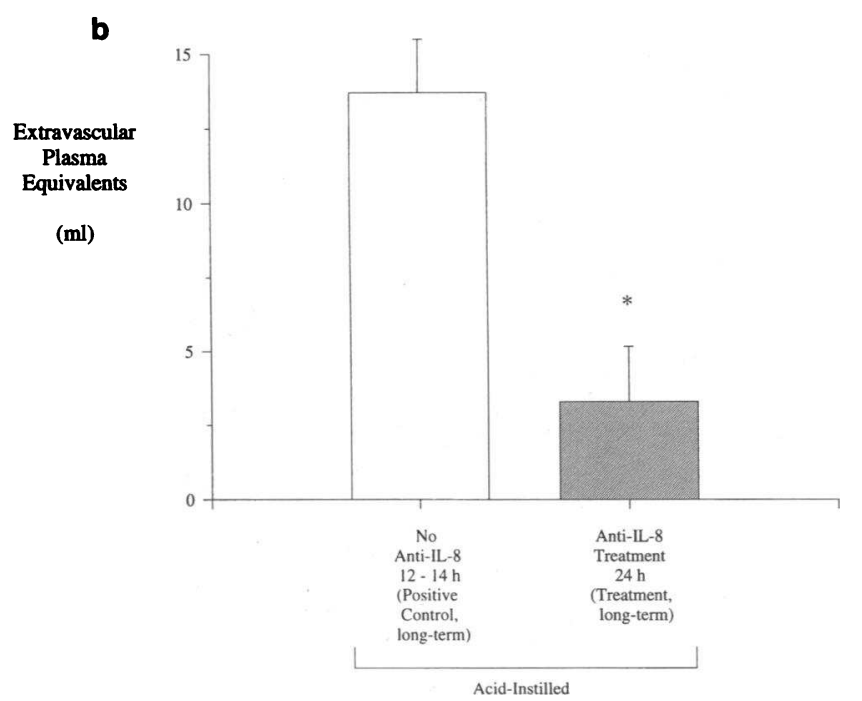

Figure 3. Endothelial permeability in the lung measured as the accumulation of the vascular protein tracer, ${ }^{131} \mathrm{I}$-albumin, in the extravascular spaces of the lung and expressed as extravascular plasma equivalents in the positive control, pretreatment, treatment, and negative control groups at $6 \mathrm{~h}(a)$, and in the positive control (long-term) group at 12$14 \mathrm{~h}$ and the treatment (long-term) group at $24 \mathrm{~h}(\mathrm{~b})$. In the short-term studies, the extravascular plasma equivalents were decreased by $70 \%$ in the pretreatment and treatment groups compared to the positive control group at $6 \mathrm{~h}(a)$. The same reduction in extravascular plasma equivalents was observed in the treatment (long-term) group at $24 \mathrm{~h}$ compared to the positive control (long-term) group at 12-14 h (b). Data are means $\pm S D, * P<0.05$ vs the positive control group $(a)$ or the positive control (long-term) group $(b),{ }^{\prime} P<0.05$ vs the negative control group $(a)$.

heart rate at any time among the experimental groups (Table I). The peak airway pressure rose in all groups within $5 \mathrm{~min}$ after instillation. While the airway pressure in the positive control group remained high, the airway pressure in the negative control group decreased by $6 \mathrm{~h}$. In the pretreatment, treatment, and neutrophil-depleted groups, the airway pressure tended to decrease, although this did not reach statistical significance (Table I). Similar findings were observed in the long-term studies (Table II).

Cell counts in bronchoalveolar lavage fluid and in periph- 

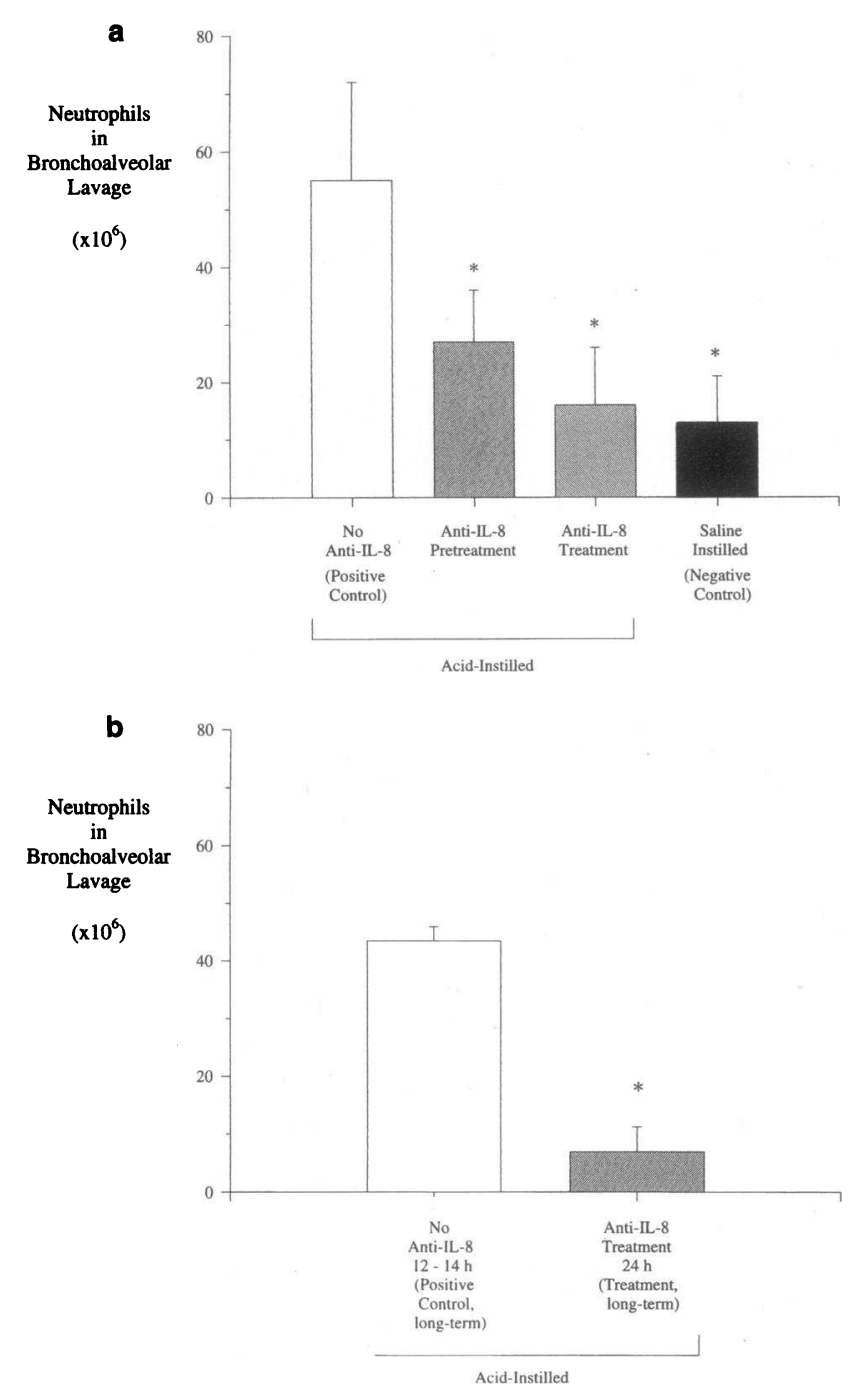

Figure 4. The number of neutrophils lavaged from the air spaces of rabbits in the positive control, pretreatment, treatment, and negative control groups at $6 \mathrm{~h}(a)$ and in the positive control (long-term) group at 12-14 h and the treatment (long-term) group at $24 \mathrm{~h}(b)$. In the short-term studies, the number of neutrophils was $50 \%$ lower in the pretreatment and treatment groups than in the positive control group and no different from that in the negative control group at $6 \mathrm{~h}(a)$. In the long-term studies, the number of neutrophils was $75 \%$ lower in the treatment (long-term) group at $24 \mathrm{~h}$ than in the positive control (longterm) group at $12-14 \mathrm{~h}(b)$. Data are means $\pm \mathrm{SD}, * P<0.05$ vs the positive control group $(a)$ or the positive control (long-term) group (b).

eral blood. In the short-term experiments, the number of PMN lavaged from the air spaces in the pretreatment and treatment groups was more than $50 \%$ lower than in the positive control group and no different from that in the negative control group (Fig. $4 a$ ). In the neutrophil-depleted group, no neutrophils were lavaged from the air spaces in any rabbit. In the long-term experiments, the number of lavaged neutrophils in the treatment (long-term) group at $24 \mathrm{~h}$ was $75 \%$ lower than in the positive control (long-term) group at $12-14 \mathrm{~h}$ (Fig. $4 \mathrm{~b}$ ). No significant difference were seen in the number of alveolar macrophages between the different groups (data not shown). In the peripheral
Table III. Free rabbit IL-8 concentrations (IL-8 not bound by the anti-IL-8 monoclonal antibody, ARIL8.2) in alveolar fluid and lavage fluid in the various experimental groups

\begin{tabular}{|c|c|c|c|}
\hline Condition & $\begin{array}{l}\text { Time of } \\
\text { sampling }\end{array}$ & $\begin{array}{c}\text { IL-8 } \\
\text { concentrations } \\
\text { in alveolar fluid }\end{array}$ & $\begin{array}{c}\text { IL-8 } \\
\text { concentration } \\
\text { in lavage fluic }\end{array}$ \\
\hline & & $n g / m l$ & $n g / m l$ \\
\hline $\begin{array}{l}\text { Positive control group } \\
\text { (HCl) }\end{array}$ & $6 \mathrm{~h}$ & $\begin{array}{l}40.5 \pm 18.2 \\
(8)\end{array}$ & $\begin{array}{c}6.7 \pm 2.5 \\
(4)\end{array}$ \\
\hline $\begin{array}{l}\text { Pretreatment group } \\
\text { (ARIL8.2, HCl) }\end{array}$ & $6 \mathrm{~h}$ & $\begin{array}{l}3.3 \pm 1.9 * \\
(6)\end{array}$ & nd \\
\hline $\begin{array}{l}\text { Treatment group } \\
\text { (HCl, ARIL 8.2) }\end{array}$ & $6 \mathrm{~h}$ & $\begin{array}{l}3.0 \pm 1.7^{*} \\
(6)\end{array}$ & $\begin{array}{c}0.6 \pm 0.3^{*} \\
\text { (3) }\end{array}$ \\
\hline $\begin{array}{l}\text { Negative control group } \\
\text { (1/3 normal saline) }\end{array}$ & $6 \mathrm{~h}$ & na & $\begin{array}{c}1.4 \pm 1.6^{*} \\
\text { (3) }\end{array}$ \\
\hline $\begin{array}{l}\text { Neutrophil depletion } \\
\text { group }(\mathrm{HCl})\end{array}$ & $6 \mathrm{~h}$ & $\begin{array}{c}31.5 \pm 3.4 \\
(4)\end{array}$ & $\begin{array}{c}26.1 \pm 5.1 \\
(4)\end{array}$ \\
\hline $\begin{array}{l}\text { Positive control (long- } \\
\text { term) group ( } \mathrm{HCl} \text { ) }\end{array}$ & $12-14 \mathrm{~h}$ & $\begin{array}{l}2.9 \pm 2.2 \\
(3)\end{array}$ & $\begin{array}{l}2.1 \pm 2.8 \\
\quad(3)\end{array}$ \\
\hline $\begin{array}{l}\text { Treatment (long-term) } \\
\text { group } \\
\text { (HCl, ARIL8.2) }\end{array}$ & $24 \mathrm{~h}$ & na & $\begin{array}{l}0.2 \pm 0.2^{\ddagger} \\
\text { (3) }\end{array}$ \\
\hline
\end{tabular}

${ }^{*} P<0.05$ vs positive control group; ${ }^{\ddagger} P<0.05$ vs positive control (long-term) group; na, sample not possible to obtain; nd, not determined; number of determinations within parentheses; values are means \pm SD.

blood, there was an identical small increase in the neutrophil count in all groups, except in the neutrophil-depleted group, where no circulating neutrophils were observed at any time during the experiment.

Concentration of free interleukin-8 in plasma, alveolar fluid, and bronchoalveolar lavage fluid. In the short-term experiments, the concentrations of free IL-8 (not bound by the antiIL-8 monoclonal antibody, ARIL8.2) in the final alveolar fluid samples were 10 -fold lower in the pretreatment and treatment groups than in the positive control group at $6 \mathrm{~h}$ (Table III). In the neutrophil-depleted group, the concentration of free IL-8 in the alveolar fluid samples at $6 \mathrm{~h}$ was no different from that in the positive control group. Because no undiluted alveolar fluid could be aspirated in the negative control group, free IL- 8 was also measured in bronchoalveolar lavage fluid. As was the case in the alveolar fluid, free IL-8 concentrations in the lavage fluid were 10-fold lower in the pretreatment and treatment groups than in the positive control group (Table III). Of interest, the free IL-8 in lavage fluid in the treatment group was not different from the negative control group (Table III). In the long-term experiments, alveolar fluid could not be aspirated from the treatment (long-term) group. However, in the lavage fluid, the free IL-8 concentrations were significantly lower in the treatment (long-term) group than in the positive control (long-term) group (Table III). In the plasma, the concentration of free IL-8 was low at all times and similar for all groups $(330 \pm 28 \mathrm{pg} / \mathrm{ml})$.

\section{Discussion}

The fundamental hypothesis of this study was that acid-induced lung injury was mediated by neutrophils recruited to the lung 
by IL-8-dependent mechanisms. Based on relevant studies of acid aspiration and of $\mathrm{IL}-8$, the steps of this hypothesis were as follows. Direct injury from the acid instilled into the lung would be limited in extent, perhaps because the acid itself is rapidly neutralized after instillation (33). Acid instillation, however, would stimulate the release of substantial quantities of IL8 from a variety of cells in the lung including airway epithelial cells, alveolar epithelial cells, and alveolar macrophages $(20$, $22,23)$. Once generated in the air spaces, IL-8 would diffuse toward the pulmonary endothelium, thereby establishing a chemotactic gradient for neutrophils. Such a gradient could be maintained either by soluble IL-8 or by IL- 8 bound to the interstitial tissues (34). After reaching the pulmonary vessels, IL-8 could then bind to the luminal endothelial surface where it would interact with circulating neutrophils $(34,35)$. The interaction of IL-8 with neutrophils would then induce up-regulation of neutrophil adhesion molecules for the endothelium, neutrophil migration through the activated endothelium, and the priming of neutrophils for activation by other mechanisms $(15,18$, $19,36,37)$. Neutrophils recruited to the lung by $I L-8$ could thus be responsible for the endothelial injury that is necessary for the formation of protein-rich pulmonary edema fluid that is characteristic of acid aspiration lung injury.

The results of this study confirm the hypothesis that acid aspiration-induced lung injury is primarily mediated by neutrophils recruited to the lung by $\mathrm{IL}-8$. First, in the rabbits instilled with acid, large numbers of neutrophils were recovered from the air spaces in association with markedly elevated quantities of IL-8. The nearly undetectable concentration of $\mathrm{IL}-8$ in the plasma in all groups supports the assumption that IL-8 was generated locally in the lung after acid aspiration. The concentration of IL-8 in the air spaces $6 \mathrm{~h}$ after acid aspiration $(41 \pm 18$ $\mathrm{ng} / \mathrm{ml}$ ) is biologically relevant; in in vitro assays of chemotaxis and neutrophil priming, IL-8 is biologically active at 10 -fold lower concentrations (38). Second, the role of the neutrophil in injuring the lung was supported by the marked reduction of lung injury after neutrophil depletion. Third, the role of IL-8 in mediating the recruitment of neutrophils and the resultant lung injury after acid instillation was established by neutralizing IL8. The anti-IL-8 antibody effectively reduced the concentrations of free IL-8 to $<10 \%$ of the concentration in the positive control (acid instilled) rabbits, to a level at the lower limit of the biological activity of IL-8 in both in vitro and in vivo studies $(38,39)$. This $\mathrm{IL}-8$ concentration was probably close to that in the negative control (saline instilled) rabbits, as judged by the similar IL-8 concentrations in the bronchoalveolar lavage fluid. The use of the anti-IL-8 monoclonal antibody led to a $>50 \%$ decrease in the neutrophil influx and, more importantly, to a dramatic reduction in the severity of the acute lung injury due to acid aspiration. After neutralization of $I L-8$, the acid-induced abnormalities in gas exchange, extravascular lung water, and lung vascular permeability were nearly completely prevented.

The three separate indices of lung injury demonstrated internally consistent and convincing results in both the short-term $(6 \mathrm{~h})$ and the long-term $(24 \mathrm{~h})$ studies. First, the alveolararterial oxygen tension difference was nearly normal in acidinstilled rabbits given the anti-IL-8 monoclonal antibody, indicating the absence of alveolar edema. Second, when IL- 8 was neutralized, the extravascular lung water in acid-instilled rabbits was not different from that in rabbits instilled with saline alone. The water-to-dry weight ratio of 4.2-4.4 grams water/gram dry lung in the pretreatment and treatment groups and in the salineinstilled control group is most consistent with mild interstitial edema. In the positive control group, on the other hand, the water-to-dry weight ratio of 7.0 grams water/gram dry lung at $6 \mathrm{~h}$ and 8.0 grams water/gram dry lung at 12-14 h clearly indicates significant alveolar edema. These differences become more obvious when the lung water is expressed as the calculated milliliters of water accumulated in the lung in excess of that in a normal rabbit lung (3.2 grams water/gram dry lung). In the positive control group at $6 \mathrm{~h}$, the excess water in both lungs was $\sim 9.2 \mathrm{ml}$, or more than threefold higher than the amount $(1.6-2.6 \mathrm{ml})$ in the negative control, pretreatment, and treatment groups. Finally, the endothelial barrier was significantly protected in the acid-instilled rabbits given the anti-IL-8 monoclonal antibody. There was a small increase in lung endothelial permeability that was not prevented by pretreatment or treatment with the monoclonal antibody to IL-8. This increase, however, was not sufficient to cause a net accumulation in extravascular lung water. A small increase in lung endothelial permeability without an accompanying increase in lung water has previously been described in sheep given an endotoxin infusion (32). Overall, once IL-8 was neutralized, the effects of acid on the lung were not different from the effects of saline alone.

Neutrophil depletion prevented the increase in lung edema and significantly decreased the alveolar-arterial oxygen tension difference and the vascular permeability after acid instillation. Although the importance of neutrophils has been reported previously after acid aspiration (8), it was necessary to demonstrate the role of neutrophils in our own model. It strengthens our conclusion that IL-8 induces lung injury indirectly, by recruiting the neutrophils that ultimately injure the lung. The fact that neutrophil depletion did not provide as complete a protection as anti-IL-8 therapy may indicate that $\mathrm{IL}-8$ can recruit other cells that participate in the injury. For example, although relatively specific for neutrophils, $\mathrm{IL}-8$ is also known to be chemotactic for T lymphocytes (40) and eosinophils (41).

The fact that the anti-IL-8 monoclonal antibody was equally effective when given $1 \mathrm{~h}$ after the acid instillation as when given $5 \mathrm{~min}$ before confirms that the development of lung injury is delayed after acid instillation. Such a time course is consistent with the kinetics expected for IL-8 expression. Studies in which IL-8 concentrations have been measured sequentially in vivo demonstrate that biologically relevant $\mathrm{IL}-8$ concentrations are first found $2 \mathrm{~h}$ after an endotoxin stimulus (29, 42). With additional time, IL-8 concentrations may be amplified further by the action of proximal macrophage-derived cytokines such as TNF- $\alpha$ or IL-1 on the nearby bystander cells, such as epithelial cells $(20,23)$. The important role of proximal cytokines in acid-induced lung injury has been suggested by an earlier study by Goldman et al. (5) in which neutralization of TNF- $\alpha$ significantly reduced the injury caused by acid-aspiration. Since TNF- $\alpha$ is a major proximal cytokine leading to the production of IL- 8 by many cells, neutralization of TNF- $\alpha$ may have been effective indirectly by reducing IL-8 concentrations. However, because TNF- $\alpha$ appears earlier than IL- 8 in the inflammatory cascade, it is unlikely that anti-TNF- $\alpha$ would be effective as late after acid-instillation as anti-IL-8. Another factor that may contribute to the relatively wide therapeutic window of anti-IL-8 (at least $1 \mathrm{~h}$ ) is that after its production, IL-8 must also diffuse to the endothelium and interact with neutrophils. Given the time necessary for IL-8 production and 
diffusion, it is conceivable that anti-IL-8 therapy given later than $1 \mathrm{~h}$ after acid aspiration would also be effective.

In any neutralization study, it is important to determine whether the antibody effectively bound and neutralized the target cytokine. First, the data support the conclusion that the antibody to IL-8 given in these experiments neutralized all IL8 in the lung. Because IL- 8 was presumably generated in the air spaces, the IL-8 concentration would have been highest in that compartment. Therefore, if the antibody given intravenously was able to bind the IL-8 in the air spaces, it would also have been able to bind the IL- 8 found at lower concentrations elsewhere in the lung. It is known that IL- 8 bound by the antibody is effectively neutralized because ARIL8.2-bound rabbit IL-8 cannot activate the rabbit IL-8 receptor in transfected cells (29). It is also known that the antibody has a high affinity for rabbit IL-8 and does not react with other closely related human cytokines (29). Because rabbit chemokines are not available to test, one cannot exclude the possibility that the anti-rabbit-IL8 antibody cross-reacts with other closely related rabbit members of the IL-8 family. This monoclonal anti-IL-8 antibody (ARIL8.2) was first tested in vivo in a rabbit model of endotoxin pleurisy, in which it inhibited neutrophil influx by $\sim 80 \%$ (29). Of note, in that study, there was a similar amount of IL8 generated in both treated and untreated groups, indicating that the antibody did not alter IL-8 production. Also, in that study, the free IL- 8 assay was first used to confirm the effective binding of the IL- 8 by the anti-IL-8 monoclonal antibody in vivo. The low concentrations of free IL-8 measured in that study and in this study are convincing evidence of effective in vivo binding and neutralization of IL-8. The low concentrations that we observed are even more impressive considering that, since bound IL- 8 can dissociate from the antibody during the ELISA dilutions, these concentrations of free IL- 8 may be overestimates of the actual free IL-8 concentrations in vivo. Therefore, we conclude that the antibody given in these experiments was of sufficient specificity, biologic activity, and concentration to neutralize IL-8 and to prevent its interaction with circulating neutrophils.

Neutralization of IL-8 reduced, but did not prevent, neutrophil influx into the air spaces of the lung, indicating the likely presence of other chemotactic factors for neutrophils. Leukotriene $\mathrm{B}_{4}\left(\mathrm{LTB}_{4}\right)$ and $\mathrm{C5a}$, for example, have been shown to be important chemotactic factors in the air spaces of the lung, based on both experimental and clinical studies $(3,7,43)$. The large reduction in the numbers of neutrophils in the air spaces after administration of the anti-IL-8 monoclonal antibody suggests that most of the neutrophils were recruited to the air spaces by IL-8, and not by $\mathrm{LTB}_{4}$ or C5a. And, more significantly, it was the neutrophils recruited to the lung by IL-8 that were associated with the development of acute lung injury.

Although the data in this study indicate that IL-8 is critical for the development of the acute lung injury after acid aspiration, it is likely that IL-8 mediates injury in conjunction with other proinflammatory molecules. When used alone, IL-8 appears to be a relatively weak neutrophil activator, although in vitro studies indicate that it is an effective primer of activation by other mechanisms $(15,18,19,36,37)$. In in vivo studies in which IL-8 alone was injected into normal human skin, neutrophils were recruited without the appearance of wheal or flare (44). Similarly, when IL-8 alone was instilled into a normal tracheal segment in dogs, neutrophils were recruited without releasing elastase or lysozyme (45). In contrast to these studies in which IL-8 was used alone, in acid aspiration lung injury, IL-8 is undoubtedly generated in conjunction with other cytokines, such as TNF- $\alpha$ and IL-1, and other inflammatory mediators, such as leukotrienes, complement fragments, and platelet activating factor. However, in spite of the different cytokines and inflammatory mediators generated after acid aspiration into the lung, inhibition of IL-8 alone is capable of preventing the experimental lung injury generated by acid aspiration in rabbits.

Aspiration of gastric contents is a major clinical cause of morbidity and mortality $(1,2)$ and effective therapy for this condition is currently unavailable. Current management is limited to positive pressure ventilation and careful management of fluid therapy. The data in this study suggest a promising therapeutic potential for anti-IL-8 therapy for this condition. There are several possible advantages of this approach. Because IL-8 is a distal cytokine, its neutralization may have more limited effects than neutralization of a more proximal, pluripotent cytokine, such as TNF- $\alpha$. Also, neutralization therapy might be required only for a short time, during the time that IL-8 is generated. In in vivo studies after endotoxin stimulation, IL-8 concentrations have returned toward normal in $<12 \mathrm{~h}(29,42)$. In our own long-term studies, at 12-14 $\mathrm{h}$ after acid aspiration, alveolar fluid IL-8 concentrations in untreated rabbits were significantly lower than at $6 \mathrm{~h}$, suggesting that a need for longterm anti-IL-8 therapy following a single acid aspiration might be unnecessary. The time of onset of the aspiration would be known with certainty in many cases because gastric aspiration is frequently witnessed (46), whereas in other clinical conditions, such as sepsis, the time of onset is often difficult to identify (47). And, most importantly, the delay in onset of the acid aspiration injury allows a clinically feasible therapeutic window of at least $1 \mathrm{~h}$. A potential limitation of anti-IL-8 therapy is that, like any antiinflammatory therapy, it might inhibit the host immunity and increase the risk of infection. Indeed, secondary bacterial pneumonia is a known complication of acid aspiration, occurring 2-10 d after aspiration (46). This issue surely deserves further experimental studies, although there are reasons to believe that anti-IL-8 therapy would not increase the risk of infection. For one, anti-IL-8 therapy did not completely prevent the neutrophil influx into the air spaces of the lungs. In fact, the total number of neutrophils in the air spaces remained high, which may be important for host defense. For another, a reduction in the underlying lung injury may reduce the risk of subsequent lung bacterial infections after acid aspiration. Finally, in mice lacking a murine homologue of an IL-8 receptor, bacterial infections have not been a problem despite an impairment in extravascular neutrophil recruitment to stimuli such as endotoxin (48). These findings are encouraging and suggest that short-term anti-IL-8 therapy might be a rational and safe approach to prevention of acid aspiration lung injury.

Compared to anticytokine approaches, one major alternative strategy for blocking neutrophil-mediated injury to the lung after acid aspiration would be to block neutrophil adhesion to the pulmonary endothelium. The factors that mediate neutrophil adhesion in the pulmonary microcirculation under different pathologic conditions, however, are complex and include physical factors (blood flow, neutrophil size and deformability, and capillary geometry) as well as an uncertain contribution from specific neutrophil and endothelial adhesion molecules (49, $50)$. For example, Doerschuk and coworkers (51) found that 
anti-CD18 therapy did not prevent neutrophil influx into the lung after acid aspiration. Anti-IL-8 therapy may prove more effective than antiadhesion strategies in this model.

In summary, acid aspiration resulted in high concentrations of IL-8 and large numbers of neutrophils in the air spaces $6 \mathrm{~h}$ after the aspiration in anesthetized, ventilated rabbits. There was severe lung injury, as indicated by poor oxygenation, pulmonary edema, and lung endothelial injury. Anti-IL-8 neutralizing monoclonal antibody given $5 \mathrm{~min}$ before or $1 \mathrm{~h}$ after the acid instillation was equally effective in preventing lung injury. Neutralization of the IL- 8 was confirmed by the finding of low free IL-8 concentrations. In the long-term studies, anti-IL-8 given $1 \mathrm{~h}$ after the acid instillation prevented death from severe acidinduced lung injury. The results of these studies have provided the first evidence of the critical role of IL-8 in mediating acute lung injury after acid aspiration. These experimental findings have potentially important implications for the treatment of acute lung injury after witnessed aspiration of gastric contents.

\section{Acknowledgments}

The authors wish to thank Oscar Osorio for valuable help with the surgical preparations of the animals, Richard Shanks for the work with the analyses of the hemoglobin and total protein, and Michael Sadick for performing the free IL-8 assays.

The studies in this report were supported by National Institutes of Health grants HL-19155, HL-51854, and HL-ES06331.

\section{References}

1. Pepe, P. E., R. T. Potkin, D. H. Reus, C. D. Hudson, and C. J. Carrico 1982. Clinical predictions of the adult respiratory distress syndrome. Am. J. Surg. 144:124-130.

2. Fowler, A. A., III., R. F. Hamman, and J. T. Good. 1983. Adult respiratory distress syndrome: risk with common predispositions. Ann. Intern. Med. 98:593597.

3. Ishii, Y., J. Kobayashi, and S. Kitamura. 1989. Chemotactic factor generation and cell accumulation in acute lung injury induced by endotracheal acid instillation. Prostaglandins Leukot. Essent. Fatty Acids. 37:65-70.

4. Kennedy, T. P., K. J. Johnson, R. G. Kunkel, P. A. Ward, P. R. Knight, and J. S. Finch. 1989. Acute acid aspiration lung injury in the rat: biphasic pathogenesis. Anesth. Analg. 69:87-92.

5. Goldman, G., R. Welbourn, L. Kobzik, C. R. Valeri, D. Shepro, and H. B. Hechtman. 1990. Tumor necrosis factor- $\alpha$ mediates acid aspiration-induced systemic organ injury. Ann. Surg. 212:513-520.

6. Goldman, G., R. Welbourn, J. M. Klausner, L. Kobzik, C. R. Valeri, D. Shepro, and H. B. Hechtman. 1991. Neutrophil accumulations due to pulmonary thromboxane synthesis mediate acid aspiration injury. J. Appl. Physiol. 70:15111517.

7. Goldman, G., R. Welbourn, L. Kobzik, C. R. Valeri, D. Shepro, and H. B. Hechtman. 1992. Synergism between leukotriene $B_{4}$ and thromboxane $A_{2}$ in mediating acid-aspiration injury. Surgery. 111:55-61.

8. Knight, P. R., G. Druskovich, A. R. Tait, and K. J. Johnson. 1992. The role of neutrophils, oxidants, and proteases in the pathogenesis of acid pulmonary injury. Anesthesiology. 77:772-778.

9. St. John, R. C., L. A. Mizer, G. C. Kindt, S. E. Weisbrode, S. A. Moore, and P. M. Dorinsky. 1993. Acid aspiration-induced acute lung injury causes leukocyte-dependent systemic organ injury. J. Appl. Physiol. 74:1994-2003.

10. Fowler, A. A., III., T. M. Hyers, B. J. Fisher, D. E. Bechard, R. M. Centor, and R. O. Webster. 1987. The adult respiratory distress syndrome: cell populations and soluble mediators in the air spaces of patients at high risk. Am. Rev. Respir. Dis. 136:1225-1231.

11. Kindt, G. C., J. E. Gadek, and J. E. Weiland. 1991. Initial recruitment of neutrophils to alveolar structures in acute lung injury. J. Appl. Physiol. 70:15751585.

12. Miller, E. J., A. B. Cohen, S. Nagao, D. Griffith, R. J. Maunder, T. R. Martin, J. P. Wiener-Kronish, M. Sticherling, E. Christophers, and M. A. Matthay. 1992. Elevated levels of NAP-1/interleukin-8 are present in the airspaces of patients with the adult respiratory distress syndrome and are associated with increased mortality. Am. Rev. Respir. Dis. 146:427-432.
13. Colditz, I. G., R. D. Zwahlen, and M. Baggiolini. 1990. Neutrophil accumulation and plasma leakage induced in vivo by neutrophil-activating peptide-1 J. Leukocyte Biol. 48:129-137.

14. Kunkel, S. L., T. Standiford, K. Kasahara, and R. M. Strieter. 1991. Interleukin-8 (IL-8): the major neutrophil chemotactic factor in the lung. Exp. Lung Res. 17:17-23.

15. Detmers, P. A., S. K. Lo, E. Olsen-Egbert, A. Walz, M. Baggiolini, and Z. A. Cohn. 1990. Neutrophil-activating protein $1 /$ interleukin 8 stimulates the binding activity of the leukocyte adhesion receptor CD11b/CD18 on human neutrophils. J. Exp. Med. 171:1155-1162.

16. Huber, A. R., S. L. Kunkel, R. F. Todd III, and S. J. Weiss. 1991. Regulation of transendothelial neutrophil migration by endogenous interleukin-8 [published errata appear in Science 1991 254:631 and 254:1435]. Science (Wash DC). 254:99-102.

17. Smith, W. B., J. R. Gamble, I. Clark-Lewis, and M. A. Vadas. 1993. Chemotactic desensitization of neutrophils demonstrates interleukin-8 (IL-8)dependent and IL-8-independent mechanisms of transmigration through cytokineactivated endothelium. Immunology. 78:491-497.

18. Yuo, A., S. Kitagawa, T. Kasahara, K. Matsushima, M. Saito, and F. Takaku. 1991. Stimulation and priming of human neutrophils by interleukin-8: cooperation with tumor necrosis factor and colony-stimulating factors. Blood. 78:2708-2714.

19. Wozniak, A., W. H. Betts, G. A. Murphy, and M. Rokicinski. 1993. Interleukin-8 primes human neutrophils for enhanced superoxide anion production. Immunology. 79:608-615.

20. Standiford, T. J., S. L. Kunkel, M. A. Basha, S. W. Chensue, J. P. Lynch III, G. B. Toews, J. Westwick, and R. M. Strieter. 1990. Interleukin-8 gene expression by a pulmonary epithelial cell line. A model for cytokine networks in the lung. J. Clin. Invest. 86:1945-1953.

21. Strieter, R. M., S. W. Chensue, M. A. Basha, T. J. Standiford, J. P. Lynch, M. Baggiolini, and S. L. Kunkel. 1990. Human alveolar macrophage gene expression of interleukin- 8 by tumor necrosis factor- $\alpha$, lipopolysaccharide, and interleukin-1 $\beta$. Am. J. Respir. Cell Mol. Biol. 2:321-326.

22. Nakamura, H., K. Yoshimura, H. A. Jaffe, and R. G. Crystal. 1991. Interleukin-8 gene expression in human bronchial epithelial cells. J. Biol. Chem. 266:19611-19617.

23. Rolfe, M. W., S. L. Kunkel, T. J. Standiford, S. W. Chensue, R. M. Allen, H. L. Evanoff, S. H. Phan, and R. M. Strieter. 1991. Pulmonary fibroblast expression of interleukin-8: a model for alveolar macrophage-derived cytokine networking. Am. J. Respir. Cell Mol. Biol. 5:493-501.

24. Boylan, A. M., C. Rüegg, K. J. Kim, C. A. Hébert, J. M. Hoeffel, R. Pytela, D. Sheppard, I. M. Goldstein, and V. C. Broaddus. 1992. Evidence of a role for mesothelial cell-derived interleukin 8 in the pathogenesis of asbestosinduced pleurisy in rabbits. J. Clin. Invest. 89:1257-1267.

25. Chollet-Martin, S., P. Montravers, C. Gibert, C. Elbim, J. M. Desmonts, J. Y. Fagon, and M. A. Gougerot-Pocidalo. 1993. High levels of interleukin-8 in the blood and alveolar spaces of patients with pneumonia and adult respiratory distress syndrome. Infect. Immun. 61:4553-4559.

26. Donnelly, S. C., R. M. Strieter, S. L. Kunkel, A. Walz, C. R. Robertson, D. C. Carter, I. S. Grant, A. J. Pollok, and C. Haslett. 1993. Interleukin-8 and development of adult respiratory distress syndrome in at-risk patient groups. Lancet. 341:643-647.

27. Mulligan, M. S., M. L. Jones, M. A. Bolanowski, M. P. Baganoff, C. L. Deppeler, D. M. Meyers, U. S. Ryan, and P. A. Ward. 1993. Inhibition of lung inflammatory reactions in rats by an anti-human IL-8 antibody. J. Immunol. 150:5585-5595.

28. Sekido, N., N. Mukaida, A. Harada, I. Nakanishi, Y. Watanabe, and K. Matsushima. 1993. Prevention of lung reperfusion injury in rabbits by a monoclonal antibody against interleukin-8. Nature (Lond.). 365:654-657.

29. Broaddus, V. C., A. M. Boylan, J. M. Hoeffel, K. J. Kim, M. Sadick, A. Chuntharapai, and C. A. Hébert. 1994. Neutralization of interleukin-8 inhibits neutrophil influx in a rabbit model of endotoxin-induced pleurisy. J. Immunol. 152:2960-2967.

30. Folkesson, H. G., F. Kheradmand, and M. A. Matthay. 1994. The effect of salt water on alveolar epithelial barrier function. Am. J. Respir. Crit. Care Med. 150:1555-1563.

31. Berthiaume, Y., N. C. Staub, and M. A. Matthay. 1987. Beta-adrenergic agonists increase lung liquid clearance in anesthetized sheep. J. Clin. Invest. 79:335-343.

32. Wiener-Kronish, J. P., K. H. Albertine, and M. A. Matthay. 1991. Differential responses of the endothelial and epithelial barriers of the lung in sheep to Escherichia coli endotoxin. J. Clin. Invest. 88:864-875.

33. Awe, W. C., W. S. Fletcher, and S. W. Jacob. 1966. The pathophysiology of aspiration pneumonitis. Surgery. 60:232-239.

34. Rot, A. 1992. Endothelial cell binding of NAP-1/IL-8: role in neutrophil emigration. Immunol. Today. 13:291-264.

35. Tanaka, Y., D. H. Adams, S. Hubscher, H. Hirano, U. Siebenlist, and S. 
Shaw. 1993. T-cell adhesion induced by proteoglycan-immobilized cytokine MIP-

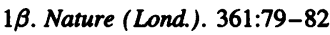

36. Carveth, H. J., J. F. Bohnsack, T. M. McIntyre, M. Baggiolini, S. M. Prescott, and G. A. Zimmerman. 1989. Neutrophil activating factor (NAF) induces polymorphonuclear leukocyte adherence to endothelial cells and to subendothelial matrix proteins. Biochem. Biophys. Res. Commun. 162:387-393.

37. Baggiolini, M., B. Dewald, and A. Walz. 1991. Activation of human neutrophils by NAP-1 and other chemotactic agonists. Adv. Exp. Med. Biol. 305:11-21.

38. Hébert, C. A., F. W. Luscinskas, J.-M. Kiely, E. A. Luis, W. C. Darbonne, G. L. Bennett, C. C. Liu, M. S. Obin, M. A. Gimbrone Jr., and J. B. Baker. 1990. Endothelial and leukocyte forms of IL-8: conversion by thrombin and interactions with neutrophils. J. Immunol. 145:3033-3040.

39. Rampart, M., J. Van Damme, L. Zonnekeyn, and A. G. Herman. 1989. Granulocyte chemotactic protein/interleukin-8 induces plasma leakage and neutrophil accumulation in rabbit skin. Am. J. Pathol. 135:21-25.

40. Larsen, C. G., A. O. Anderson, E. Appella, J. J. Oppenheim, and K. Matsushima. 1989. The neutrophil-activating protein (NAP-1) is also chemotactic for T lymphocytes. Science (Wash. DC). 243:1464-1466.

41. Erger, R. A., and T. B. Casale. 1995. Interleukin-8 is a potent mediator of eosinophil chemotaxis through endothelium and epithelium. Am. J. Physiol. 268:L117-L122.

42. Harada, A., N. Sekido, K. Kuno, M. Akiyama, T. Kasahara, I. Nakanishi, N. Mukaida, and K. Matsushima. 1993. Expression of recombinant rabbit IL-8 in Escherichia coli and establishment of the essential involvement of IL-8 in recruiting neutrophils into lipopolysaccharide-induced inflammatory site of rabbit skin. Int. Immunol. 5:681-690.
43. Martin, T. R., B. P. Pistorese, E. Y. Chi, R. B. Goodman, and M. A. Matthay. 1989. Effects of leukotriene $B_{4}$ in the human lung. Recruitment of neutrophils into the alveolar spaces without a change in protein permeability. $J$. Clin. Invest. 84:1609-1619.

44. Leonard, E. J., T. Yoshimura, S. Tanaka, and M. Raffeld. 1991. Neutrophil recruitment by intradermally injected neutrophil attractant/activation protein-1. J. Invest. Dermatol. 96:690-694.

45. Jorens, P. G., J. B. Y. Richman-Eisenstat, B. P. Housset, P. D. Graf, I. F. Ueki, J. Olesch, and J. A. Nadel. 1992. Interleukin-8 induces neutrophil accumulation but not protease secretion in the canine trachea. Am. J. Physiol. 263:L708L713.

46. Bynum, L. J., and A. K. Pierce. 1976. Pulmonary aspiration of gastric contents. Am. Rev. Respir. Dis. 114:1129-1136.

47. Rubin, D. B., J. P. Wiener-Kronish, J. F. Murray, D. R. Green, J. Turner, J. M. Luce, A. B. Montgomery, J. D. Marks, and M. A. Matthay. 1990. Elevated von Willebrand factor antigen is an early plasma predictor of acute lung injury in nonpulmonary sepsis syndrome. J. Clin. Invest. 86:474-480.

48. Cacalano, G., J. Lee, K. Kikly, A. M. Ryan, S. Pitts-Meek, B. Hultgren, W. I. Wood, and M. W. Moore. 1994. Neutrophil and B cell expansion in mice that lack the murine IL-8 receptor homolog. Science (Wash. DC). 265:682-684.

49. Wortel, C. H., and C. M. Doerschuk. 1993. Neutrophils and neutrophilendothelial cell adhesion in adult respiratory distress syndrome. $N$. Horizons. $1: 631-637$

50. Ward, P. A. 1995. Adhesion molecule knockouts: one step forward and one step backward. J. Clin. Invest. 95:1425.

51. Doerschuk, C. M., R. K. Winn, H. O. Coxson, and J. M. Harlan. 1990 CD18-dependent and -independent mechanisms of neutrophil emigration in the pulmonary and systemic microcirculation of rabbits. J. Immunol. 144:2327-2333. 